\title{
Editorial: Spatiotemporal Modelling for Construction Project Management
}

\author{
Adel Francis $^{1 *}$, Borja Garcia de Soto ${ }^{2}$ and Shabtai Isaac ${ }^{3}$ \\ ${ }^{1}$ Construction Engineering Department, Ėcole de Technologie Supèrieure (ĖTS), Montreal, QC, Canada, ${ }^{2}$ S.M.A.R.T. \\ Construction Research Group, Division of Engineering, New York University Abu Dhabi (NYUAD), Abu Dhabi, United Arab \\ Emirates, ${ }^{3}$ Department of Structural Engineering, Ben-Gurion University of the Negev, Beersheba, Israel
}

Keywords: spatiotemporal, modelling, construction project management, scheduling, 4D, bim

Editorial on the Research Topic

Spatiotemporal Modelling for Construction Project Management

It is our great pleasure to welcome you to this Research Topic of the Frontiers in Built Environment Journal: Spatiotemporal Modelling for Construction Project Management.

Traditional methods for modeling building projects are no longer sufficient for showing the work sequence, circulation, and supply flows of construction sites. The critical path logic ignores the spatial aspects of site occupation related to operations and teams' rotation, traffic, and intermediate stocks. The extensive use of the critical path logic produces a complex network that is hard to follow and update. The planning and management of building projects should tackle the coordination of works and the management of limited site space, traffic, and supplies. Activities cannot be performed without the resources available, and resources cannot be used beyond the capacity of workplaces. Otherwise, workspace congestion will negatively affect the flow of works, leading to errors and omissions and, consequently, low productivity and economic losses.

The adoption of Building Information Modeling (BIM) and four-dimensional (4D) simulation is forcing the construction industry to adapt its contractual, operational, and technical modes. New complementary concepts have emerged to meet those challenges, particularly the Last-Planner system, Takt-Time Planning, and Space Planning. Their objectives are to increase collaboration, ensure smooth flows of information, improve productivity, reduce all types of waste in the process, and stabilize production. In addition, Space and Takt-Time planning links the spatial and temporal aspects of construction projects, promotes efficient use of the site, defines optimal site occupancy rates, and ensures the suitable rotation of the workforce in the different spaces on site.

The objective of this Research Topic is to discuss the latest developments in the field of space planning and spatiotemporal implementation in order to improve the management of building construction projects. Methods that use graphic modeling to optimize the construction process and the various flows under the constraints of limited space, resources, and time. The goal is to increase productivity, improve collaboration, stabilize production, and to ensure smooth information, production, and supply flows at project sites. This Research Topic includes the following five papers.

France-Mensah et al. present an integrated planning platform for short- to long-term plans for different functional groups in State Highway Agencies (SHAs). The aim is to increase the effectiveness of collaboration for developing and maintaining transportation infrastructure. The use of heterogeneous information systems challenges efforts to perform a spatial-temporal analysis of candidate projects proposed by these functional groups. To address this challenge, this paper presents an integrated framework to improve the collaborative planning of highway projects by SHAs. The proposed framework facilitates proactive and spatial-temporal cross-functional 
planning of candidate highway projects recommended by different functional groups in highway agencies.

Wu and García de Soto propose a spatiotemporal model to optimize the lifting task scheduling of tower cranes that uses a tabu search and 4-D simulation. Their model accounts for the availability of work areas, in addition to the no-load and loaded lifting processes, the pre- and post- lifting operations that are primarily caused by material preparation. In addition, transfer times are integrated into the lifting task time model. As a proofof-concept, the authors used an example with two tower cranes and 28 lifting tasks. They found that the average total time of the optimized lifting task scheduling can be reduced by about $26 \%$. The model's outcome can be used to create a $4-\mathrm{D}$ simulation to visualize the lifting tasks, which can improve coordination and safety.

Francis proposes the Chronographical site-spatial-temporal modeling of construction operations. The model combines the management of space and time. The goal of the model is to linearize the construction operations; optimize the use of spaces and avoid congestion and conflicts; and ensure the rotation of teams and operations in the different site locations. The model optimizes the schedule and facilitates the monitoring of the progress of the construction operations. The modeling strategy is based on the design of artifacts that show the dynamic evolution of the occupancy of different areas and floors on the construction site. Three modeling approaches, namely, sitespatio-temporal modeling, time-allocation, and time-location are discussed.

Bascoul et al. introduce Location Site (LoSite), a simple program using Excel that assists with the visualization of work being done in construction projects. The tool promotes transparency in the daily coordination of workspace among different trades. The authors provide insights into the successes and limitations found during the implementation of such a tool in a real construction project. LoSite shows that space-use visualization, even on a large-scale project, can be done effectively using software that is broadly used by construction participants.

Ardila and Francis present an extensive review and an assessment of the state of the art of the spatiotemporal planning of construction projects. The paper uses systematic research to present a synthesis of the most important scientific developments in the domain, their evolution, and addresses their possible impacts on the construction industry. The main objective is to present a timeline that categorizes the scientific contributions using two different classifications: (i) the Research Topics (e.g., theoretical concepts, workflow, and material flow), and (ii) the research approaches (e.g., mathematical, and decision systems).

\section{AUTHOR CONTRIBUTIONS}

AF: editorial draft. BGS: summary addition of Wu and García de Soto and Bascoul et al. SI: revision and edition. All authors contributed to the article and approved the submitted version.

Conflict of Interest: The authors declare that the research was conducted in the absence of any commercial or financial relationships that could be construed as a potential conflict of interest.

Copyright $\odot 2020$ Francis, Garcia de Soto and Isaac. This is an open-access article distributed under the terms of the Creative Commons Attribution License (CC BY). The use, distribution or reproduction in other forums is permitted, provided the original author(s) and the copyright owner(s) are credited and that the original publication in this journal is cited, in accordance with accepted academic practice. No use, distribution or reproduction is permitted which does not comply with these terms. 